\title{
TECNÓLOGO: CRISE DE IDENTIDADE E CORROSÃO DO CARÁTER
}

\section{TECHNOLOGIST: CRISIS OF IDENTITY AND CORROSION OF CHARACTER}

\author{
Marcelo Santos Marques ${ }^{1}$ \\ Joao Eudes Moreira da Silva ${ }^{2}$
}

\section{RESUMO}

Objetivando adequar o currículo das instituições de ensino que compõem a Rede Federal de Educação Profissional, Científica e Tecnológica as necessidades imediatas do mercado, o governo federal, no ano de 1997, instituiu uma reforma da educação profissional. À época, ele extinguiu o ensino integrado e implantou três modalidades de ensino profissionalizante: o básico, o técnico e o tecnológico. Este último voltado para atender às demandas de consumo de mão de obra, emanadas da automação flexível. No ano de 1999, o então Centro Federal de Educação Tecnológica do Ceará - CEFET-CE instituiu os seus primeiros Cursos Superiores Tecnólogos - CST: Mecatrônica e Telemática, os quais se constituíram em objeto do presente levantamento. Passados vinte anos das reformas, muita coisa mudou, em termos de aparato tecnológico e de relações de trabalho, sem que o tecnólogo logre obter o reconhecimento profissional no mercado de trabalho. A Associação Nacional dos Tecnólogos - ANT e o Conselho Federal de Engenharia, Arquitetura e Agronomia - CONFEA lançaram a Cartilha do tecnólogo (2010), com o objetivo de obter reconhecimento desses profissionais, bem como lhes conferir identidade. A análise deste artigo corporativo e de outros documentos correlatos como a Declaração de Bolonha (1999) e o Relatório de Jacques Delors (2010), à luz da teoria do valor de Karl Marx $(1985 ; 1887)$ e da tendência à qualificação-desqualificante da força de trabalho de Aécio Oliveira (2006) e de Marcelo Marques (2016) constituem a base fundante que irá permitir refletir sobre a estrutura que conforma a identidade coletiva e o caráter do ser tecnólogo.

Palavras-chave: Tecnólogo. Identidade. Caráter. Qualificação-desqualificante.

\begin{abstract}
In 1997, the federal government instituted a reform at the professional education level, aiming at adjusting the curricula of the education institutions that are part of the Rede Federal de Educação Profissional, Científica e Tecnológica to the immediate market needs. At that time, it extinguished/ ended the integrated education and implemented three professional education modalities: basic, technical and technological. The latter targeted at attending the workforce demanded by the new flexible automation practices. In 1999, the by then Centro Federal de Educação Tecnológica do Ceará - CEFET-CE instituted its first Technologist Tertiary education courses - (Cursos Superiores Teconológicos - CST): Mechatronics and Telematics, both the object of the present analysis. Twenty years after the reform, many things changed in terms of the technological machines and the working relation, without the technologist achieving its professional recognition in the labour market. The Technologist National Associations - ANT and the Engineering, Architecture and Agronomy Federal Council CONFEA published the "Technologist handbook" aiming at obtain these professionals recognition, as well as confer them an identity. Based on the analysis of this cooperated guide
\end{abstract}

\footnotetext{
${ }^{1}$ Professor Titular do Departamento de Licenciatura e Ensino Médio do Instituto Federal de Educação. Ciencia e Tecnologia do Ceará. ${ }^{2}$ Professor Titular do Departamento de Licenciatura e Ensino Médio do Instituto Federal de Educação. Ciencia e Tecnologia do Ceará. Revista Labor Fortaleza/CE, jul/dez 2018 n 20, Vol. 01, pp. 37-53 ISSN 1983-5000
} 
and other documents related to the Bologna Declaration (1999) and the Jacques Delors Reports (2010), supported by Karl Marx's value theory $(1985,1887)$ and the workforce qualification-disqualification tendency by Aécio Oliveira (2006) and Marcelo Marques (2016), this investigation will reflect on the structure that shapes the collective identity and the character of the technologist subject.

Keywords : Technologist , identity, character, Qualification-disqualifying

\section{APRESENTAÇÃO}

Em 1999, a maior parte das antigas Escolas Técnicas Federais - ETF foram transformadas em Centros Federais de Educação Tecnológica - CEFET. Essa transformação permitiu que estas instituições pudessem oferecer o ensino superior profissionalizante. Naquele mesmo ano, o então Centro Federal de Educação Tecnológica do Ceará - CEFETCE, hoje Instituto Federal de Educação, Ciência e Tecnologia do Ceará - IFCE, pôs em funcionamento seus dois primeiros Cursos Superiores Tecnológicos - CST: Mecatrônica e Telemática $^{3}$. O primeiro agregava conhecimentos das áreas de mecânica, eletrônica, eletrotécnica, informática, telemetria, robótica, automação de equipamentos e de processos manufaturados automáticos. O segundo encerrava a aposição de dois campos profissionais: telecomunicações e informática, consubstanciando a designada teleinformática.

Dois anos antes, o governo federal promoveu uma reforma na educação profissional, por meio do Decreto Lei $n^{\circ} 2.208$ (BRASIL, 1997), pondo fim ao Ensino Técnico Integrado ao Ensino Médio ${ }^{4}$. No ensejo, inseriu duas outras modalidades de ensino em nível técnico: uma concomitante e outra sequenciada. A primeira oportunizava ao discente cursar o Ensino Médio e o Ensino Técnico simultaneamente. A segunda lhe facultava seguir o Ensino Técnico após o término do Médio. Essas duas modalidades formativas objetivavam preparar trabalhadores para exercerem suas atividades em plantas fabris fordistas, para executarem ações repetitivas como as encenadas por Charles Chaplin, em Tempos Modernos (1936).

O governo instituiu ainda, dois outros níveis de cursos profissionalizantes: o Básico e o Tecnológico. O primeiro não era regulado por qualquer normatização curricular e tinha por meta certificar mão de obra de pequena formação, não importando o nível de

3Mecatrônica e Telemática serviram de objeto de estudos quando Marcelo Santos Marques cursou o Doutorado em Sociologia, junto à Universidade Federal do Ceará - UFC, entre os anos de 2005 e 2009, defendendo a Tese: Em busca dos egressos do CEFETCE: a qualificação profissional no foco da crítica do sistema do capital. No ano de 2016, esta Tese foi publicada na forma de livro sob a designação Crise do capital: educação e qualificação-desqualificante. Estas formulações iluminam as reflexões ora efetuadas.

4 Ao instituir o Decreto Lei $n^{\circ}$. 5.154/04, o presidente Luís Inácio Lula da Silva (2003 - 2011) revogou o Decreto Lei nº 2.208/97, implantando uma nova reforma no âmbito da Rede Federal de Educação Profissional, Científica e Tecnológica, que permitiu o retorno do Ensino Técnico Integrado ao Ensino Médio, mantendo os três níveis de ensino profissionalizante. Aprofundando a condição flexível do ensino ministrado o Decreto adensou novas modalidades formativas (BRASIL, 2004).

Revista Labor Fortaleza/CE, jul/dez 2018 n² 20, Vol. 01, pp. 37-53 ISSN 1983-5000 
aprendizagem precedente. $\mathrm{O}$ segundo seria direcionado a aquisição dos novos paradigmas produtivos demandados pela automação industrial e o uso da microeletrônica. Ao invés da ação mecânica reprisada que caracterizava o fordismo, o tecnólogo se direcionava a gestão e a supervisão dos complexos automáticos produtivos. Suas competências e habilidades demarcavam adequabilidade, flexibilidade e multifuncionalidade.

Esses três traçados formativos se direcionavam a distintos públicos alvos e apresentavam dispares projetos de qualificação profissional: os Cursos Básicos visavam chancelar trabalhadores sem qualificação formal; o Nível Técnico era focado na ação formativa monolítica típica da indústria de Henri Ford objetivando formar técnicos unidirecionais e; o Ensino Superior Tecnológico era concentrado nos saberes multivalentes e nos exercícios multiusos emanado do Toyotismo, que deveriam ser os objetos de estudos dos Cursos de Tecnologia.

A ideia governamental era tornar a formação profissional amoldável à heterogeneidade produtiva que tipificava, e ainda tipifica os parques fabris brasileiros e formar trabalhadores na medida da demanda empresarial. Por isso, em sua concepção, era fundamental quebrar com a base curricular rígida das antigas Escolas Técnicas Federais dando a ela maior versatilidade e adequabilidade as exigências do mercado. Ao instituir a formação profissional flexível, o Decreto Lei no 2.208 (BRASIL, 1997) se apresentou uma “aula inaugural" sobre as práticas permanentes de remodelagem formativa.

Consoante o discurso oficial, era necessário atrair Investimentos Externos Diretos - IED e usar este capital estrangeiro para modernizar o parque produtivo brasileiro, investir em tecnociência e conferir diversidade a formação profissional. Com base nessa asserção de caris econômico, tecnológico e educativo, disseminaram-se os Cursos Tecnológicos por todo o Brasil, se espargindo por diferentes áreas de conhecimentos. De acordo com o Catálogo Nacional de Cursos Superiores, do Ministério da Educação - MEC, nos dias de hoje há CST em diferentes campos: ambiente e saúde; controle e processos industriais; desenvolvimento educacional e social; gestão e negócios; informação e comunicação; infraestrutura; militar; produção alimentícia; produção cultural e design; produção industrial; recursos naturais; segurança e turismo, hospitalidade e lazer (BRASIL, 2016). Esse levantamento é efetuado ano a ano pela Secretaria de Educação Profissional e Tecnológica do Ministério da Educação Setec/MEC.

A expansão do ensino tecnológico no Brasil também se efetivou por intermédio da ampliação da oferta de vagas diretas. Segundo a Cartilha do Tecnólogo (2010) até o ano de 
2002 foram constituídos mais de 800 Cursos Superiores de Tecnologia, com aproximadamente 150 mil estudantes matriculados, sendo as instituições privadas responsáveis pela maior quantidade de cursos ofertados (ANT; CONFEA, 2010b). Não obstante a amplitude das áreas de cobertura dos cursos de tecnologia e da ampliação da quantidade de matrículas efetuadas, esses dados não são suficientes para permitir entender a complexidade desse fenômeno formativo.

Desde a edição do Decreto Lei no 2.208 (BRASIL, 1997) para cá, vinte anos se passaram. O Brasil tomou para si a "mundialização" (CHESNAIS, 1996, p. 24), financeirizou sua economia, automatizou suas plantas fabris, fortaleceu o setor de serviços, adotou as commodities como modelo padrão de exportação e se reprimarizou. Em decorrência desse modelo de desenvolvimento contraditório, verificamos a modernização de suas forças produtivas: meios de produção foram integralizados pela aplicação do Programmable Logic Controller - PLC; a telemetria ao possibilitar o acionamento de componentes mecânicos por comandos eletrônicos posicionados alhures conferiu agilidade a produção mercantil; desenvolveram-se as Tecnologias da Informação e da Comunicação - TIC, interconectando o capital, on line, 24 horas por dia pelas vias do ciberespaço. O Vale do Silício foi guindado à condição de sonho de consumo da intelligentsia econômica. Em contrapartida, decaímos na vida líquida da modernidade (BAUMAN, 2007).

O conjungir desses saberes técnico-científicos ressignificaram o "mundo do trabalho", sobretudo nas formas de consumo da força de trabalho. A velha estrutura estandardizada, herdada do fordismo, acompanhada do operário-massa, foi submetida a processos de reengenharia dando lugar a uma produção enxuta e à organização por células e linhas reconfiguráveis, de acordo com a mercadoria produzida. A fusão de áreas de conhecimento propiciou uma nova divisão técnica do trabalho, gerando novos campos profissionais como, por exemplo, ocorreu com as áreas de mecatrônica e de telemática. $\mathrm{O}$ esforço desmesurado típico de Prometeu Acorrentado, inerente à clássica estrutura fordista, deu lugar ao modelo de um trabalhador "tipo ideal", que faz uso de ferramentas high-tech, como software, e whatsapp no cotidiano de seu ofício. Essas novas modalidades de consumo das mercadorias pessoais dos trabalhadores constituem o pano de fundo que permite identificar qual seja a identidade e o caráter do profissional tecnólogo.

Esse vendaval de forças produtivas autorreferenciadas, acrescidas de reengenharias operacionais, eleva a composição orgânica do capital em favor do trabalho morto (máquinas automáticas). $\mathrm{O}$ ambiente tomado por tecnologias cibernético- 
informacionais deveria fazer supor que os tecnólogos logo seriam integrados pelo mercado de trabalho na sua condição de profissionais de nível superior. Afinal, eles encerram o padrão flexo e prurivalente exigido pelo capital em nossa contemporaneidade. Porém, no Brasil não foi isso que se observou na ordem prática. A Petrobrás, enquanto empresa líder do mercado nacional, não os admitem em seus editais para efeito de concurso público e as empresas privadas tão somente ignoram-nos. Se os mecatrônicos são acolhidos pelo Conselho Federal de Engenharia, Arquitetura e Agronomia - CONFEA, os telemáticos sequer dispõem de um órgão regulador de sua profissão.

O Conselho Federal em colaboração com a Associação Nacional dos Tecnólogos - ANT - entidade fundada quando do I Encontro Nacional dos Tecnólogos da Engenharia, realizado no ano de 2006 - crê que os Cursos Tecnológicos foram alvos de preconceitos dos meios acadêmicos universitários, sobremodo das universidades federais (ANT; CONFEA, 2010b). De sua parte, a professora Lucília Machado (2008) credita esse não reconhecimento a "estranhamentos" derivados de "hibridismo", "mal resolvido", fruto da incompleta conjunção entre a formação profissional e o ensino superior:

Esses estranhamentos derivam da condição de nascimento desses cursos e da
profissão de Tecnólogo: são filhos de diferentes pais ou de condições diversas, ou
seja, originários do cruzamento de espécies que a tradição insiste em não confundir
ou misturar (educação profissional e ensino superior), trazem as marcas de um
hibridismo ainda mal resolvido, que expressa as contradições mais profundas da
divisão social do trabalho (MACHADO, 2008, p. 17).

Segundo os signatários da Cartilha: o caráter e a identidade da profissão (2010b) somente no ano de 2002 as universidades públicas reconheceram os tecnólogos como profissionais de nível superior passando a recebê-los em seus cursos de Pós-graduação stricto sensu e lato sensu (ANT; CONFEA, 2010b). O reconhecimento de suas chancelas pelas Instituições Federais de Ensino Superior - IFES não encerrou o conflito que encerra a condição de ser tecnólogo. Faltavam-lhes as "bênçãos" do mercado.

Já se vão quase vinte anos que os ares liberalizantes circundam o Brasil e, a despeito dos esforços, as entidades de representação não conseguiram dar aos tecnólogos uma condição identitária distintiva e desejada. Em um esforço para lhes conferir reconhecimento, essas entidades publicaram a já mencionada Cartilha do tecnólogo (2010). Ela se refere à existência de preconceitos, a uma crise de pertencimento social e uma ausência de amorpróprio que alcança aos profissionais tecnólogos. Em contrapartida, sugerem o esclarecimento quanto ao caráter da profissão e quanto a uma identidade que os constituem (ANT; CONFEA, 2010a; 2010b). 
A peça corporativa, mais do que o reconhecimento da existência de uma crise de identidade profissional entre os tecnólogos, revela propensões sobre a forma de o capital consumir a força de trabalho no tempo presente. Para verificar de modo claro e preciso a identidade dos tecnólogos, como afiançam os signatários da Cartilha (2010), faz-se necessário que se analise como se dá o funcionamento do sistema do capital em sua atualidade, assinalando suas tendências históricas e contradições sociometabólicas. À luz da recuperação de seu traçado histórico e do constructo lógico que o abaliza será possível perceber as disposições apontadas para o consumo da mão de obra no tempo presente. O que por sua vez permitirá perceber a identidade do tecnólogo e refletir sobre seu caráter.

\section{MARX, FORMAS DE CONSUMO DAS FORÇAS DE TRABALHO E IDENTIDADES}

A conjugação das forças produtivas emanadas da robótica e da microeletrônica advindas do desenvolvimento científico-tecnológico permite que o capital simultaneamente otimize o tempo da produção e potencialize a operosidade da mão de obra. Tudo se passa como se o savoir-faire estivesse concentrado nas mãos de trabalhadores altamente qualificados e as novas forças produtivas automáticas postas a seu serviço. Quem observa a pletora dos meios de produção microeletrônicos e enxerga nas novas relações de trabalho um vínculo autônomo frente às relações de produção multivalentes, põe em relevo a importância dos produtores diretos no trato dos meios de produção reconfiguráveis. Essa visão se reflete na Cartilha do Tecnólogo (2010). Em sua óptica, é como se o capital estivesse passando o controle da concepção aos trabalhadores. Não é isso o que efetivamente ocorre.

Os apologistas da modernidade tecnológica não percebem que a adoção de novas tecnologias autorreferenciadas acelera o movimento da contradição central do sistema do capital, refreando a base do valor (tempo de trabalho). Contradição esta que tem lugar na redução da ação direta do produtor imediato (trabalho vivo), em favor de procedimentos cristalizados nos sistemas de máquinas, instalações fabris e processos automatizados (trabalho objetivado). Como o tempo de trabalho humano desprendido diretamente para a produção de uma mercadoria corresponde à substância que determina seu valor, à medida que vão sendo integralizados os procedimentos fabris, vai se restringindo a base da valorização, evidenciado como opera a contradição processual que demarca a substituição do trabalho vivo pelo trabalho morto (MARX, 1987, vol. 2), tornando patente a impossibilidade de seu sistema se expandir de modo ad infinitum.

De sua parte, o transcurso histórico do capital compreende três momentos hegemônicos: cooperação simples, divisão do trabalho e grande indústria (MARX, 1985). 
Esses modos de produzir predominantes refletem a passagem do trabalhador de centro da produção para a condição de apêndice. Inicialmente, o capital impôs o controle externo sobre a atividade dos artífices (cooperação simples); depois os sujeitou à manufatura e à fragmentação dos seus afazeres (divisão do trabalho); por fim, os submeteu ao ritmo ditado pelo sistema de máquinas ferramentas (grande indústria). Agora, "El trabajo ya no aparece tanto como recluido en el proceso de producción, sino que más bien el hombre se comporta como supervisor y regulador con respecto al proceso de producción mismo" (MARX, 1987, vol. 2, p. 228).

O capital subsumiu a si o trabalho, a natureza, a ciência e a tecnologia, reduzindoos a condição de meros fatores produtivos. Nesse processo ele transformou o "mundo da produção" em um espaço de domínio abstrato onde muitas vezes as mercadorias ganham os ares da imaterialidade. O cenário comum prevalecente nas modernas empresas baseadas na tecnologia high-tech é demarcado pela existência de meios de produção automáticos, que prescindem da presença física e espiritual dos produtores imediatos, redundando no designado “desemprego estrutural". Restam aos trabalhadores remanescentes atividades supervisórias e de regulação. Suas ações são demarcadas pela polivalência e flexibilidade.

Se o capital ganhou em magnitude científico-tecnológica, os trabalhadores perderam sua magistralidade produtiva em favor dos maquinismos autorreferenciados. De centro da produção da riqueza material, o trabalhador foi reduzido a uma mera condição de apêndice. No tempo presente, com a disseminação de tecnologias da automação essa tendência de perda da virtuose se acelerou geometricamente tornando que a presença física e espiritual de produtores imediatos redundante. Em decorrência, os trabalhadores se transformaram em uma mão de obra crescentemente supérflua (MÉSZÁROS, 2002,), já não mais integrável a ordem capitalista ${ }^{5}$.

A recuperação da tendência lógica do sistema sociometabólico prevalente e de sua histórica possibilita verificar a atual tendência quanto ao esgotamento do conteúdo do trabalho do produtor imediato. Aplicada à educação é possível perceber que o capital qualifica aos trabalhadores, desqualificando-os. Os saberes, antes pertencentes aos produtores diretos, são transferidos para máquinas multivalentes, dando expressão ao processo de qualificaçãodesqualificante da força de trabalho. (OLIVEIRA, 2006; MARQUES, 2016). Por isso, os

\footnotetext{
${ }^{5}$ A Foxconn - que, entre vários outros produtos, faz os iPhones e iPads da Apple - já anunciou que pretende "empregar" 1 milhão de robôs até 2014. Dados preparados pela consultoria Gavekal mostram que o custo unitário de um robô industrial atingiu cerca de US\$ 48 mil no ano passado, uma diferença pequena para os US\$ 44 mil pagos a um funcionário pela gigante de montagem Foxconn durante dois anos. (LANDIM e CRUZ, 2011. Adaptado do Jornal Estado de São Paulo, de 31 de março de 2012).

Revista Labor Fortaleza/CE, jul/dez 2018 n² 20, Vol. 01, pp. 37-53 ISSN 1983-5000
} 
tecnólogos estão sujeitos às mesmas disposições que apontam para o esvaziamento da virtuose dos trabalhadores em geral.

O título da publicação da Cartilha do tecnólogo (2010) trouxe à mente a obra $A$ Corrosão do Caráter, de autoria do sociólogo norte-americano Richard Sennett (2005). Seu livro toma como fio condutor os efeitos que o recente avanço científico-tecnológico desencadeou sobre o cotidiano da vida social. Analisa a atual estrutura do trabalho, com ênfase na flexibilidade e na ação em curto prazo, e assinala os seus efeitos sobre a psique dos trabalhadores. No que concerne à análise da condição de ser do tecnólogo, assume condição de relevo o capítulo em que esse autor discorre sobre as transformações no cotidiano do trabalho, no interior de uma padaria de Boston, após a sua informatização, permitindo, por analogia, refletir a identidade tecnólogo.

Sennett visita a padaria quando a produção ainda apresentava uma dimensão artesanal e se baseava no métier do padeiro, e passados vinte e cinco anos, discorre sobre as condições de trabalho da mesma panificadora, só que agora ela havia se modernizado, transformando-se em um complexo alimentício, baseado na automação. Agora, o domínio da informática se tornou a pré-condição para a contratação de trabalhadores. Isso, a despeito de prescindirem desse conhecimento no dia a dia de seu ofício.

Os trabalhadores digitam comandos de um programa de um software autoprogramado e o forno microeletrônico realiza o serviço autonomamente. Não obstante a ação da tecnologia pode-se perceber o elevado grau de dissociação do trabalhador imediato, quando uma empregada da padaria se vangloriando de seu conhecimento informático assevera: “- [...] 'padaria, sapataria, gráfica é só dizer’[...]” (SENNETT, 2005, p. 87). A despeito do sentido meritocrático da constituição do discurso, seu texto revela a mais completa indiferença quanto ao conteúdo do trabalho de padeiro e um intenso conflito quanto à identidade de ser panificador.

A alteração do caráter dos trabalhadores e as incertezas quanto as suas identidades profissionais podem, por semelhança, alcançar a outros campos profissionais: são caixas de bancos subordinados aos sistemas contábeis microeletrônicos; são códigos de barras que dispensam o conhecimento matemático; são trabalhadores rurais substituídos por máquinas automáticas do agronegócio; são indústrias produzindo a despeito da mediação dos trabalhadores; são mecatrônicos e telemáticos atuando como suportes de sistemas eletrônicos digitais etc. Em decorrência, o trabalhador tem convivido com a perda de vínculo com seu fazer produtivo e decaído em um processo de reificação quanto ao conteúdo do trabalho. 


\section{TECNÓlOgOS ENTRE A ONTOLOGIA E A PEDAGOGIA DO CAPITAL}

Nos dias de hoje, há um debate sociológico sobre quais efeitos que essas tecnologias podem provocar sobre as relações de trabalho e sobre o modo que as forças de trabalho são consumidas. Muitos dos teóricos que debatem o "mundo do trabalho" acreditam que há uma polarização entre trabalhadores decantados como altamente qualificados e àqueles não qualificados. Afirmam que a automação possibilitará a aquisição de saberes complexos por àqueles mais intelectualizados que se dedicam a concepção. Não obstante, quando suas análises se debruçam sobre os trabalhadores que executam atividades de simples realização suas conclusões seguem por trilhas totalmente diversas. Eles remetem-se ao seu embrutecimento. É como se estivéssemos em meio a uma polaridade que intelectualiza uns e estupidifica outros. Nessa perspectiva, os primeiros trabalhadores corresponderiam ao trabalho tornado ato ontológico e os últimos estariam fadados à canga e ao desaparecimento de suas funções a medida do avanço da automação.

Lucília Machado, em Profissional Tecnólogo e sua Formação (2008), advoga à tese de que o ensino superior tecnológico encarna uma síntese da justaposição de saberes tecnocientíficos e de proficiências multifuncionais ligadas ao ensino politênico. Para dar luz a sua crença, toma para si a tarefa de refletir sobre a identidade do tecnólogo. Para ela, a curta duração da maioria desses cursos tem contribuído para a sua expansão, mas tem motivado que carreguem consigo estigmas preconceituosos que os fazem serem percebidos como cursos de segunda categoria e de baixo prestígio social. Em resposta, a professora argumenta que estes trabalhadores provenientes dos CST encerram os ideais ontológicos e os princípios formativos gregos de techne e logos consagrados na Paidéia:

\footnotetext{
O conhecimento tecnológico, embora multifacetado e abrangente, se unifica no seu objeto: os meios técnicos e os modos operatórios de conceber, organizar, gerenciar e executar o trabalho nas mais diversas áreas profissionais ou mesmo de atividades lúdicas e de consumo próprio. Orienta-se, sem dúvida, para fins práticos e resolutórios e tem uma racionalidade intrínseca: a tecnológica, uma correlação entre techne (arte) e logos (saberes, ciência, filosofia) (MACHADO, 2008, p. 22 e 23).
}

Limitada a uma leitura trans-histórica, a educadora não se apercebe de que, a despeito do caráter aparente intelectivo de alguns ramos de trabalho, todos os setores estão sendo tragados pela mesma lógica do valor, que os impele, progressivamente, a preterir a presença do trabalho humano em razão do trabalho pretérito (máquinas). Não alcança as disposições contraditórias que operam sobre o conjunto dos trabalhadores e sobre suas ações 
formativas. Não compreende que sob o domínio das relações reificadas prevalentes na moderna sociedade produtora de mercadorias, degrada-se o próprio significado do termo "qualificação" (BRAVERMAN, 1987).

A professora não leva em consideração a contradição central do sistema do capital e nem as tendências de consumo da força de trabalho em meio à automação do processo produtivo. Mesmo os trabalhadores que estiverem operando, por meio de sofisticados comandos eletrônicos, ou aqueles estejam realizando suas atividades no "chão de fábrica" fazendo uso de chaves de grifo, todos serão alcançados pelo desenvolvimento progressivo da contradição processual: a substituição do trabalho vivo pelo trabalho morto. Ela não percebe que a ação cerebral também é passível de separação, tal qual ocorreu com a concepção e a execução, e está sujeita a repetições tautológicas. Sobre a contradição capital - trabalho e seus efeitos sobre o "mundo do trabalho" Marx (1994) afirma que ela atingirá o conjunto dos trabalhadores:

A oposição entre capital e trabalho assalariado desenvolve-se, assim, até sua plena
contradição. E no interior desta que o capital aparece como meio não somente de
depreciação da capacidade viva de trabalho, mas também como meio de torna-la
supérflua. Em determinados processos isso ocorre por completo; em outros, esta
redução se efetua até que se alcance o menor número possível no interior do
conjunto da produção. O trabalho necessário coloca-se, então, imediatamente como
população supérflua, como excedente populacional - aquela massa incapaz de
gerara mais-trabalho (1994, p. 106).

Percebe-se, a partir da reflexão marxiana que de modo desigual e combinado todos os trabalhadores serão abarcados pela tendência que valoriza-desvalorizando suas mercadorias pessoais. Por isso, é indiferente se os produtores executam afazeres ligados à concepção ou à execução, cada um a seu modo será alcançado pelo movimento da contradição central do sistema do capital.

Claro está que o boon dos Cursos Superiores Tecnológicos no Brasil está umbilicalmente ligado à tendência do sistema do capital em atuar fazendo uso crescente da ciência e da tecnologia em detrimento da presença dos trabalhadores diretos. A automação flexível exige a remodelagem dos trabalhadores de modo a torna-los reconfiguráveis e adequáveis, consoante às necessidades mais diretas do processo de valorização. O tecnólogo pode ser considerado um profissional "máximo genérico"6, multifacetado, eclético e modelável. Desse modo, sua formação deve se pautar por estudos horizontais cotejando

6 Quando da pesquisa do Doutorado em Sociologia, realizado na UFC (2006 - 2009) indagou-se a um telemático sobre a questão da identidade desse profissional. Em resposta, ele afirmou que: “- Os cursos de tecnologia, eles deviam assumir o fenômeno como de fato ele é. Criar um Curso com um nome só. Chamar de 'especialista em Tecnologia da Informação'. Que é um nome, máximo genérico possível. Vamos assumir a verdade. Esse profissional vai ter um nome genérico". O trabalhador "máximo genérico" eis o sentido de ser do tecnólogo.

Revista Labor Fortaleza/CE, jul/dez 2018 n² 20, Vol. 01, pp. 37-53 ISSN 1983-5000 
dispares regiões de inquérito. A generalidade redunda na completa perda de identidade funcional de quaisquer trabalhadores.

Como expressão real da crise indenitária e da corrosão do caráter, se é plausível encontrar mecatrônicos e telemáticos efetuando atividades complexas de reengenharia integrando plantas fabris, do mesmo modo também é admissível localizá-los realizando trabalhos de baixo domínio cognitivo, como a operação de supervisórios, atividade tão insidiosa $^{7}$ como àquelas realizadas pelos clássicos exércitos de operários fabris estandardizados. Em decorrência, aprofunda-se o grau de dissociação existente entre a teoria e prática. Não obstante, encontrá-los exercendo atividades pueris comparadas ao nível de sua certificação não lhes é novidade. Afinal, sob a ótica prevalente, o trabalho deve ocorrer a despeito do conhecimento dos trabalhadores (BRAVERMAN, 1987).

A Cartilha (2010), por outro lado, afirma que os tecnólogos estão em sintonia com as novas forças produtivas reprogramáveis demandas pelo mercado. Em sua concepção, suas competências atitudinais e habilidades devem ter a posse de múltiplas valências que lhes permitam o comportamento polivalente requerido pelo capital. Em função dessa adequabilidade mercadológica e da desespecialização formativa, o texto exposto lança mão da ideia de competências em forma de bricolagem: "competências em recortes" (ANT; CONFEA, 2010a, p. 25; 2010b, p. 35).

Com o desejo de conferir identidade aos tecnólogos e lhes propiciar uma expressão de caráter coletivo, o escrito corporativo busca ancorar-se em dois documentos institucionais que têm se constituído em base fundante para as reformas educacionais disseminadas do capital mundial: Declaração de Bolonha (2009) e a Educação um tesouro a descobrir: relatório para Unesco da Comissão Internacional sobre Educação para o século XXI, mais conhecido como Relatório de Jacques Delors (2010). Em suas óticas esses dois tratados institucionais correspondem a marcos no processo de organização e desenvolvimento dos Cursos Superiores Tecnológicos:

O Protocolo de Bolonha, associado ao Relatório de Jacques Delors, sinaliza para a educação a ser praticada no século XXI, notadamente em relação à educação superior. Nesse contexto, a educação tecnológica se tornou um importante referencial para os cursos de bacharelados, a partir de um maior equilíbrio entre ciência e tecnologia, de currículos mais flexíveis, dinâmicos e sintonizados com a realidade do mundo do trabalho (ANT; CONFEA, 2010b, p. 18). 
O Relatório Jacques Delors (2010), de responsabilidade da Organização das Nações Unidas para a Educação, a Ciência e a Cultura - UNESCO aponta Os Quatro Pilares da Educação: aprender a conhecer, aprender a fazer, aprender a conviver e aprender a ser (UNESCO, 2010). Eles constituem os preceitos segundo os quais a educação deve dar conta dos aspectos psicossociais de crianças e adolescentes, sem se prenderem tão somente aos elementos cognitivos. Também conferem luz às necessidades de qualificação profissional requeridas pelo capital. Para os autores do documento os conhecimentos clássicos adquiridos pelos trabalhadores no domínio de seu ofício, são agora classificados como arcaicos. A aquisição de um savoir-faire acumulado no decurso de toda uma vida profissional perdeu atualidade. Por isso, devem ser substituídas por um sistema de competências e habilidades baseado em posturas procedimentais, como: "incentivo à iniciativa", "trabalho em equipe", "trabalho por conta própria", "empreendedorismo" e "sinergias realistas" (IBIDEM, 2010, p. 29).

Como os maquinismos e instalações estão integrados aos processos produtivos e como eles se tornaram cada vez mais "inteligentes”, não carecem da ação física e espiritual do trabalhador vivo no ato de trabalho sejam eles vinculados ao planejamento, supervisão ou à execução operacional. Como a mecânica autorreferenciada já não mais demanda tantos saberes dos trabalhadores diretos, as noções comportamentais são mais desejadas que a posse conhecimentos formais. O capital valoriza a flexibilidade do trabalhador e a sua condição de "habituação" (BRAVERMAN, 1987, p. 123) às novas relações de produção.

A adequação do ensino às novas demandas reconfiguráveis da produção denota o sentido que toma a pedagogia do capital em nossos dias (OLIVEIRA, 2006; MARQUES, 2016). Os conteúdos perderam o lugar de primazia em nome de competências e habilidades atitudinais. O tecnólogo deve ser formado para a polivalência funcional e para sucessivas remodelagens, conforme as transmutações produtivas levadas a termo pela tecnociência. Esse é o sentido imediatamente interessado que a governança do capital mundial almeja para o ensino superior.

A Declaração de Bolonha (1999) representa a peça-chave para que se possam vislumbrar quais as finalidades perquiridas por aqueles que fazem a educação profissional nos dias atuais. Seu texto propõe montar um sistema de educação de terceiro grau unificado em toda a Europa, conformando o designado "Espaço Europeu do Ensino Superior". Como regra, o documento se remete a necessidade de adequação do ensino de cada país do "Velho Continente" às novas demandas da tecnociência. Para tal, sugere que seus currículos sejam 
tornados compatíveis entre si, de modo a "incentivar a mobilidade de estudantes" (DECLARAÇÃO DE BOLONHA, 1999, p. 2), lhes oportunizando cursem disciplinas em qualquer instituição de ensino superior da Europa. Desse modo, se estabelecerá a competitividade no âmbito do Sistema Europeu do Ensino Superior. A flexibilidade proposta aos discentes também se realizará junto aos docentes. Eles poderão efetuar estudos e pesquisas em todo o território da "Europa do Conhecimento" (IBIDEM, p. 1).

A ordem é tomar para si o ideal da “indispensável flexibilidade dos cursos" (UNESCO, 2010, p. 21), reconfigurar as instituições de ensino e habituar discentes e docentes às novas necessidades de consumo das forças de trabalho pelo capital. Em relação aos últimos a orientação formativa compulsória é apresentada sem subterfúgios: "Sua vida profissional deve ser organizada de tal modo que estejam em condições, até mesmo, sejam obrigados a aprimorar sua arte e a se beneficiar de experiências vividas em diversas esferas da vida econômica, social e cultural" (IBIDEM, p. 35. Grifo nosso).

No conjunto, essas medidas assinaladas pelo Protocolo de Bolonha (1999) e pelo Relatório Jacques Delors (2010) se constituem em elementos estruturantes para a realização de reformas nos diversos sistemas nacionais de ensino de todo o mundo. Aplicadas, elas serão capazes de cominar multe referência e flexibilidade às ações educativas, em consonância ao modelo moldável exigido pelo capital em nossa contemporaneidade. Seguindo as trilhas desses documentos institucionais, a Cartilha do Tecnólogo (2010) assevera que os Cursos Superiores Tecnológicos se consubstanciaram em referência para todos os cursos de terceiro grau. Em sua concepção, isso ocorre exatamente devido à presença de matrizes curriculares "ágeis e flexíveis" e a sua adequabilidade as necessidades imediatas do mercado de trabalho:

\footnotetext{
A natureza dos cursos superiores de tecnologia implica currículos ágeis e flexíveis, capazes de responder positivamente às demandas do mundo do trabalho. Essa concepção de currículos ganha força na medida em que o Protocolo de Bolonha estimula as reformas e orienta para um modelo de educação superior muito próximo daquilo que vem sendo praticado na educação tecnológica desde a década de 1960 (ANT; CONFEA, 2010a, p. 15; 2010b, p. 17).
}

De sua parte, os tecnólogos são apresentados pelos autores da Cartilha (2010) como os profissionais requeridos pelo século XXI e que encarnam o novo éthos da adaptabilidade. Agindo assim, eles pretendem conformar o trabalhador genérico requerido pelo capital. Mas, em que consiste a tão decantada flexibilidade do trabalhador? A resposta de Sennett (2005) a essa indagação nos remete à corrosão do vértice que perfaz a estrutura do ser humano: 
A palavra "flexibilidade" entrou na língua inglesa no século quinze. Seu sentido derivou originalmente da simples observação de que, embora a árvore se dobrasse ao vento, seus galhos sempre voltavam à posição normal. [...] Em termos ideais, o comportamento humano flexível deve ter a mesma força tênsil: ser adaptável a circunstâncias variáveis, mas não quebrado por elas. [...] As práticas de flexibilidade, porém, concentram-se mais nas forças que dobram as pessoas (2005, p. 53).

O "tradicional" bacharel apresenta uma base formativa que lhe possibilita vergar frente aos dissabores da vida e retornar ao ponto original. Já os “modernos" tecnólogos são trabalhadores de formação horizontal, versátil e prurivalente. Nesse sentido, muitas vezes, lhes falta um "prumo" que os possibilite conferir um sentido de permanência a sua atuação profissional, ficando a mercê das vicissitudes do mercado. Eles dispõem de um domínio de várias áreas correlatas entre si, podendo atuar indistintamente em díspares ramos profissionais. Não obstante, nada lhes garante que, frente a um vendaval, retornem ao ponto de origem.

\section{CONSIDERAÇÕES FINAIS}

A identidade e o caráter do tecnólogo estão marcados pela lógica do tempo presente e do aqui-agora. Cabe ao trabalhador, individualmente, ajustar-se às necessidades imediatas de consumo de sua mercadoria pessoal, dispondo-a consoante as condições ditadas pelo mercado de trabalho. A maleabilidade tornou-se a expressão do caráter de sua profissão tecnológica, revelando a possibilidade desse trabalhador pôr em ação filamentos de conhecimentos, aplicados aos pedaços como "competências em recortes", de modo a responder mais rapidamente às exigências produtivas.

A conformação de um trabalhador "máximo genérico", maleável e reconfigurável, para ser consumido na velocidade da automação, compõe a base movediça sobre a qual se assenta a identidade e o caráter do tecnólogo. Formação para a adequabilidade, eis o sentido conflitivo que consubstancia sua constituição indenitária. Sua formação instrumental lhes confere a possibilidade de redesenhar traçados profissionais de modo a trabalhar em díspares ramos produtivos. Só que as condições mutantes não lhes possibilitam conferir um enredo duradouro para suas vidas, estando entregues às variações do mercado. Quanto mais esculpível for sua "causa material” (trabalho genérico), maior será a corrosão de sua "causa formal" (psique/caráter) ${ }^{8}$.

8 As expressões “causa formal” e "causa material” são aqui utilizadas em analogia a intenção de Aristóteles. Para o filósofo grego, a primeira causalidade diz respeito ao ser e a segunda a composição dos objetos em transformação. Assim, se um homem pega uma pedra de mármore e a esculpe, o artesão compreende a causa formal (essencial) e a pedra tão somente sua causa material (objeto).

Revista Labor Fortaleza/CE, jul//dez 2018 n 20, Vol. 01, pp. 37-53 ISSN 1983-5000 
A lógica que impulsionou o desenvolvimento dos meios de produção capitalistas baseou-se no alargamento dos antagonismos que retroalimentam a contradição dialética fundante do sistema do capital (trabalho vivo - trabalho morto). Assim, todo o aparato da acumulação flexível e os decorrentes rearranjos de reengenharia se deram em conformidade às suas exigências sociometabólicas. A formatação instantânea de trabalhadores, para atender às demandas imediatas de reprodução mercantil, vai de encontro aos interesses dos produtores diretos. A multifacetada desespecialização dos tecnólogos, que se constituiu no moderno mito da qualificação multivalente, não transformou esses trabalhadores em profissionais mais qualificados. O ensino superior advindo de Bolonha e de Delors está apresado à mesma dialética que retroalimenta o processo de valorização-desvalorização do conjunto da força de trabalho. Como poderiam os tecnólogos em geral e os mecatrônicos e telemáticos em particular, escaparem das mesmas amarras que aprisionam a todos os trabalhadores indistintamente.

\section{REFERÊNCIAS BIBLIOGRÁFICAS}

ANT; CONFEA. Cartilha do tecnólogo: o caráter e a identidade da profissão. Brasília: Confea, 2010a. 30 p. Disponível em: <http://www.ant.org.br/cartilha_tecnologo.pdf >. Acesso em: 01 nov. 2010.

ANT; CONFEA. Cartilha do tecnólogo: o caráter e a identidade da profissão. Brasília: Confea, 2010b. 37 p. Disponível em:

<http://www.creaba.org.br/Imagens/FCKimagens/01-2012/cartilha_tecnologo(1).pdf.>. Acesso em: 05 set. 2017.

BRASIL. Catálogo Nacional de Cursos Superiores de Tecnologia. Brasília: Ministério da Educação, 2016. 193 p. Disponível em:

$<$ http://portal.mec.gov.br/index.php?option=com_docman\&view=download\&alias $=44501$ cncst-2016-3edc-pdf\&category_slug=junho-2016-pdf\&Itemid=30192>. Acesso em: 20 ago. 2017.

BRASIL. Decreto Lei $n^{\circ} .2 .208$, de 17 de abril de 1997. Regulamenta o $§ 2^{\circ}$ do art. 36 e os arts. 39 a 42 da Lei n $^{\circ}$ 9.394, de 20 de dezembro de 1996, que estabelece as diretrizes e bases da educação nacional. República Federativa do Brasil, Poder Executivo, Brasília, DF, 17 abr. 1997. Disponível em:

<http://www.planalto.gov.br/ccivil_03/decreto/d2208.htm>. Acesso em: 20 jul. 2017.

BRASIL. Decreto Lei $n^{\circ}$. 5.154, de 23 de julho de 2004. Regulamenta o $§ 2$ o do art. 36 e os arts. 39 a 41 da Lei no 9.394, de 20 de dezembro de 1996, que estabelece as diretrizes e bases da educação nacional, e dá outras providências. República Federativa do Brasil, Poder Executivo, Brasília, DF, 23 jul. 2004. Disponível em:

<http://www.planalto.gov.br/ccivil_03/_ato2004-2006/2004/decreto/d5154.htm>. Acesso em: 20 jul. 2017. 
BRASIL. Portaria MEC n 646, de 14 de maio de 1997. Regulamenta a implantação do disposto nos artigos 39 a 42 da Lei Federal no 9.394/96 e no Decreto Federal no 2.208/97 e dá outras providências. República Federativa do Brasil, Ministério da Educação, Brasília, DF, 14 mai. 1997. Disponível em:

<http://portal.mec.gov.br/setec/arquivos/pdf/PMEC646_97.pdf>. Acesso em: 20 jul. 2017.

BRASIL. Educação Profissional: “Concepções, Experiências e Propostas”. Anais do Seminário Educação Profissional: "Concepções, Experiências e Propostas”. Brasília: MEC/SEMTEC/PROEP, 2003. 214 p.

BAUMAN, Z. Tempos líquidos. 1. ed. Rio de Janeiro: Jorge Zahar Ed., 2007. 119 p.

BRAVERMAN, H. Trabalho e Capital Monopolista: A degradação do trabalho no século XX. 3. ed. Rio de Janeiro: Editora Guanabara, 1987. 379 p.

CHASNAIS, F. A mundialização do capital. 1. ed. São Paulo: Xamã, 1996. 335 p.

DECLARAÇÃO DE BOLONHA. Portugal: Bolonha, 1999. 2 p. Disponível em: $<$ http://media.ehea.info/file/Ministerial_conferences/05/3/1999_Bologna_Declaration_Portug uese_553053.pdf >. Acesso em: 28 mai. 2017.

LANDIM, R.; CRUZ, R. Cada vez mais barato, robô já substitui até trabalhador chinês $\mathbf{O}$ Estado de S. Paulo, São Paulo, 31 março de 2012. Economia \& Negócios.

Disponível em: <http://economia.estadao.com.br/noticias/geral,cada-vez-mais-barato-robo-jasubstitui-ate-trabalhador-chines,108113e>. Acesso em: 08 set. 2017.

MACHADO, L. O Profissional Tecnólogo e sua Formação. Revista da RET - Rede de Estudos do Trabalho - Ano II - Número 3 - 2008. Marília: Unesp, 2008. 30 p. Disponível em: < http://www.ant.org.br/cartilha_tecnologo.pdf >. Acesso em: 01 set. 2017.

MARQUES, M. Capital em crise: educação e qualificação desqualificante. 1. ed. Fortaleza: Expressão Gráfica e Editora, 2016. 380 p.

MARQUES, M. A qualificação profissional no foco da crítica ao sistema do capital: em busca dos egressos do CEFETCE. 2009. 387 f. Tese (Doutorado em Sociologia) Departamento de Ciências Sociais, Universidade Federal do Ceará, Fortaleza, 2009.

MARX, K. Elementos Fundamentales para la Crítica de la Economia Política (Grundrisse). Vol. 2., Espanha: Editora Siglo Veintitiuno, 1987. 493 p.

MARX, K. Manuscrito de 1861-1863. Maquinaria e Trabalho Vivo (Os Efeitos da Mecanização Sobre o Trabalhador). In: Crítica Marxista, Vol. 1, nº I, $2^{\mathrm{a}}$ ed. São Paulo: Ed. Brasilense, 1994. 103-110 p.

MARX, K. O Capital: crítica da economia política. Vol. 1. 2. ed. São Paulo: Ed. Nova Cultural, 1985. $301 \mathrm{p}$.

MÉSZÁROS, I. Para além do capital: rumo a uma teoria da transição. 1. ed. São Paulo: Boitempo Editorial e Editora da UNICAMP, 2002. 1102 p. 
SENNETT, R. A Corrosão do Caráter: conseqüências pessoais do trabalho no novo capitalismo. 9. ed. Rio de Janeiro: Ed. Record, 2005. 204 p.

OLIVEIRA, A. Para uma socioeconomia política da transição: possibilidades e limites da economia solidária. 2006. 322 f. Tese (Doutorado em Sociologia) - Departamento de Ciências Sociais, Universidade Federal do Ceará, Fortaleza, 2006. Fortaleza: Tese de Doutorado de Sociologia - UFC, 2006.

UNESCO. Educação um tesouro a descobrir: relatório para Unesco da Comissão Internacional sobre Educação para o século XXI. (Relatório de Jacques Delors). 2010. Brasília: Setor de Educação da Representação da UNESCO no Brasil. 43 p. Disponível em: <http://unesdoc.unesco.org/images/0010/001095/109590por.pdf >. Acesso em: jul. 2017. 